\title{
DETERMINATION OF SIZE-INDEPENDENT FRACTURE ENERGY OF GRANITE USING PEAK LOADS OF BEAMS
}

\author{
SHUTONG YANG* AND XIAOZHI HU \\ * Ocean University of China \\ Qingdao, P.R.China \\ e-mail: shutongyang2013@163.com \\ ${ }^{\dagger}$ University of Western Australia \\ Perth, Australia \\ e-mail: xiao.zhi.hu@uwa.edu.au
}

Key words: Granite, Local fracture energy, Peak load, Size-independent fracture energy

\begin{abstract}
Fracture energy, defined as the amount of energy necessary to create one unit area of a crack, is a very important parameter in analyzing the behavior of quasi-brittle materials such as concrete, mortar, rock, et al.. The size-independent fracture energy of concrete and mortar can be obtained according to boundary effect theory. The intention of this paper is to determine the sizeindependent fracture energy of granite by virtue of the peak loads of three-point-bending notched beams. An analytical model was presented to correlate the peak loads with the crack-tip local fracture energy in granite beams. A fracture test was then carried out on granite beams with two depths, i.e., $30 \mathrm{~mm}$ and $70 \mathrm{~mm}$. For the beams with depths of $30 \mathrm{~mm}$, the notches are cut with lengths from $3 \mathrm{~mm}$ to $18 \mathrm{~mm}$. For the beams with depths of $70 \mathrm{~mm}$, the notch lengths vary from 2 $\mathrm{mm}$ to $53 \mathrm{~mm}$. The average value of the maximum tensile stress at the fictitious crack-tip is adopted as $8 \mathrm{MPa}$. Upon the comparison between the analytically predicted peak loads and the experimentally determined ones, the correlation between the crack-tip local fracture energy and notch length can be obtained. It can be found that the value of crack-tip local fracture energy almost keeps $300 \mathrm{~N} / \mathrm{m}$ without free boundary effect for the notch lengths from $9 \mathrm{~mm}$ to $18 \mathrm{~mm}$ in the beams with depths of $30 \mathrm{~mm}$ and for the notch lengths from $10 \mathrm{~mm}$ to $53 \mathrm{~mm}$ in the beams with depths of $70 \mathrm{~mm}$. Thus, the size-independent fracture energy is $300 \mathrm{~N} / \mathrm{m}$ for this type of granite.
\end{abstract}

\section{INTRODUCTION}

Fracture energy, defined as the amount of energy necessary to create one unit area of a crack, is a very important parameter in analyzing the behaviors of cementitious materials or quasi-brittle materials, such as concrete, mortar, rock, etc. It is usually determined based on the work-of-fracture method recommended by RILEM [1]. But it is found to be much dependent on the sizes and shapes of the specimens. Various studies attempted to explain the size effect in fracture energy. The size effect model by Bažant et al. $[2,3]$ and the multi-fractal scaling law by Carpinteri et al. [4-6] gave much valuable explanations on the size effect. But both of the models only concentrate the effect of the width or depth of the tested specimen and the notchto-depth ratio is invariable. Based on the FCM [7], $\mathrm{Hu}$ et al. [8-13] emphasize that the key mechanism for the size effect should be the 
interaction between the FPZ and the boundary of specimen not the physical size itself, and then develop the theory of boundary effect. The width and length of the FPZ related to local fracture energy are found to vary along the ligament of specimen and decreases sharply towards the back free boundary [8-10]. Thus, a bi-linear model for the local fracture energy distribution is presented including a horizontal line with the value of sizeindependent or true fracture energy $G_{\mathrm{F}}$ and a linearly descending part approaching zero at the back free boundary of specimen [14]. The boundary effect phenomenon was verified experimentally by Abdalla and Karihaloo [15] and the $G_{\mathrm{F}}$ is simply determined by testing a single size specimen with only two distinctly different notch-to-depth ratios.

Muralidhara et al. [16] pointed out a fictitious boundary effect at the initial notch tip using acoustic emission data recorded from three-point-bending notched concrete beams and presented a tri-linear local fracture energy distribution model which consists of an ascending line from zero at the initial crack-tip, a horizontal line and a descending portion approaching zero at the back free boundary. The tri-linear model has been verified experimentally by other researchers [17, 18]. Moreover, the size-independent fracture energy of high strength concrete is determined by the tri-linear model $[19,20]$. The authors proposed an analytical approach to correlate the load-carrying capacity of three-pointbending notched concrete [21] or mortar [22] beams with local fracture energy at the cohesive crack-tip region, and determine the variation of the crack-tip local fracture energy with the initial crack length. A modified trilinear local fracture energy distribution model was presented, which indicates the front boundary effect. The bi-linear model by Duan et al. [14] is accurate enough only if the initial crack length is longer than $30 \%$ of the specimen depth [22].

The boundary effect and size-independent fracture energy have been well determined for concrete and mortar. As another type of quasibrittle materials, the fracture properties of rock are very similar to those of concrete and mortar [23]. Fracture energy is also a very important parameter in describing the quasibrittle fracture process in rock. The intention of this paper is to determine the boundary effect and the size-independent fracture energy of granite. An analytical model is first proposed in this paper to correlate the cracktip local fracture energy with the peak loads of three-point-bending notched granite beams. The regions affected by the front and back free boundary effects and the size-independent fracture energy are then obtained based on the comparison between the analytically predicted and experimentally measured peak loads.

\section{ANALYTICAL MODEL}

A three-point-bending notched granite beam with an initial crack length $a_{0}$ at the midspan is shown in Fig. $1 . b$ and $h$ are the width and depth of beam, respectively. $L$ represents the span of beam and $L=4 h$.

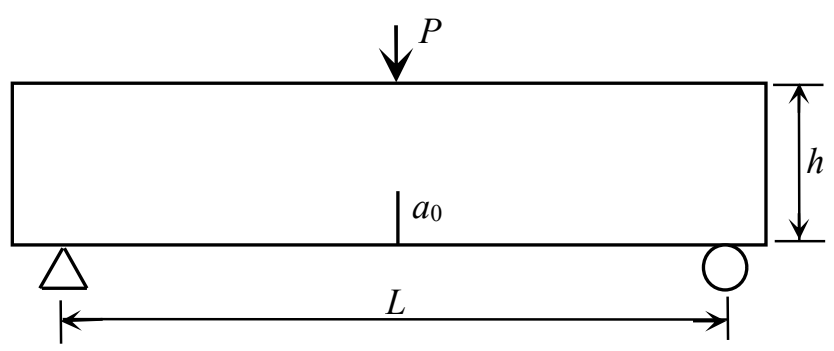

Figure 1: Three-point-bending notched granite beam

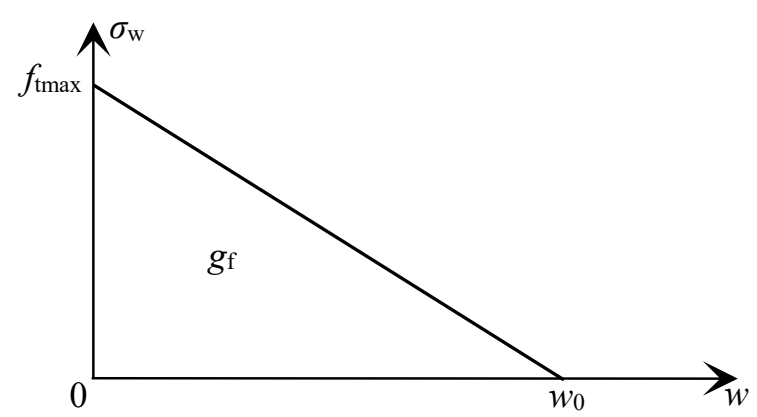

Figure 2: Single-linear model for $\sigma_{\mathrm{w}}-w$ relationship

When the initial crack starts to propagate in the granite, a fracture process zone appears ahead of the crack-tip for quasi-brittle materials and can be described based on FCM [7]. The relationship between the cohesive stress $\sigma_{\mathrm{w}}$ and crack opening width $w$ in the fictitious crack is assumed to be single-linear 
as shown in Fig. 2, which reads

$$
\sigma_{\mathrm{w}}=f_{t \max }\left(1-\frac{f_{t \text { max }}}{2 g_{f}} w\right)
$$

Herein, the area underneath the $\sigma_{\mathrm{w}}-w$ curve is the local fracture energy $g_{\mathrm{f}}$ of granite. $f_{\mathrm{tmax}}$ is micro-critical stress at the fictitious crack-tip. $w_{0}$ is the maximum crack opening width when the cohesive stress is reduced to zero.

The distributions of stress and strain along the depth of granite beam in the critical crosssection before the ultimate state are shown in Fig. 3.

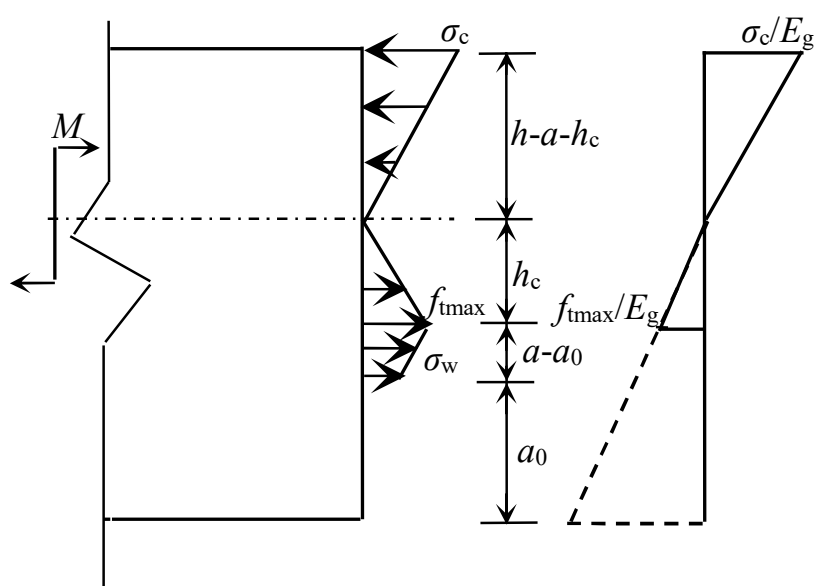

Figure 3: Distributions of stress and strain in the critical cross-section

where $E_{\mathrm{g}}$ is the elastic modulus of granite and $a$ is the effective crack length after the first cracking initiation. Moreover, it is assumed that the $g_{\mathrm{f}}$ is constant as the cohesive crack-tip local fracture energy in the quasi-brittle crack growth region.

According to the linear strain's distribution in Fig. 3, we have

$$
\sigma_{\mathrm{c}}=\frac{h-a-h_{c}}{h_{c}} f_{t \max }
$$

The equilibrium condition of forces in the critical section gives

$$
h_{c}=\frac{(h-a)^{2}}{2(h-a)+\left(2-\frac{f_{t \max }}{2 g_{f}} w_{t}\right)\left(a-a_{0}\right)}
$$

where $w_{\mathrm{t}}$ is the width of the initial crack-tip. Moreover, the bending moment $M$ can be obtained as follows according to the equilibrium condition of forces in Fig. 3, i.e.,

$$
\begin{aligned}
& M=\frac{1}{3} \sigma_{c} b\left(h-a-h_{c}\right)^{2}+\frac{1}{3} f_{t \text { max }} b h_{c}^{2}+ \\
& \int_{h_{c}}^{h_{c}+a-a_{0}} \sigma_{w} b x d x
\end{aligned}
$$

Substituting Eqs. (1)-(3) into Eq. (4), the bending moment $M$ can be expressed as a function of $a$ and $w_{\mathrm{t}}$, i.e., $M\left(a, w_{\mathrm{t}}\right)$.

Moreover, the crack mouth opening displacement $C M O D$ is given as follows by Tada et al. [24].

$$
\begin{aligned}
& C M O D=\frac{24 M a}{E_{g} b h^{2}}\left[0.76-2.28 \frac{a}{h}+3.87\left(\frac{a}{h}\right)^{2}-2.04\left(\frac{a}{h}\right)^{3}\right. \\
& \left.+0.66\left(\frac{h}{h-a}\right)^{2}\right]
\end{aligned}
$$

The relationship between $C M O D$ and $w_{\mathrm{t}}$ is

$$
C M O D=\frac{a w_{t}}{a-a_{0}}
$$

Inserting Eqs. (1), (2), (3), (4) and (6) into Eq. (5) yields an equilibrium equation with respect to $a$ and $w_{\mathrm{t}}$ as follows.

$$
M_{1}\left(a, w_{t}\right)=0
$$

Based on the Lagrange Multiplier Method, a Lagrange function $\Phi\left(a, w_{\mathrm{t}}, \lambda\right)$ should be established as follows.

$$
\Phi\left(a, w_{t}, \lambda\right)=M\left(a, w_{t}\right)+\lambda \times M_{1}\left(a, w_{t}\right)
$$

Herein, $\lambda$ is a unknown parameter to be solved. By applying the following conditions,

$$
\frac{\partial \Phi}{\partial a}=\frac{\partial \Phi}{\partial w_{t}}=\frac{\partial \Phi}{\partial \lambda}=0
$$

three equations are given. The critical effective crack length $a_{\mathrm{c}}$ and the critical crack-tip opening width $C T O D_{\mathrm{c}}$ are obtained by solving the three equations. Then the maximum bending moment $M_{\max }$ can be given by inserting $a=a_{\mathrm{c}}$ and $w_{\mathrm{t}}=C T O D_{\mathrm{c}}$ into Eq. (4). The peak load $P_{\max }$ is yielded by Eq. (10) as follows.

$$
P_{\max }=\frac{4 M_{\max }}{L}-\frac{W}{2}
$$

where $W$ is the self-weight of the granite beam.

Obviously, the $P_{\max }$ is determined by two important material parameters, i.e., the micro- 
critical tensile stress $f_{\text {tmax }}$ and the crack-tip local fracture energy $g_{f}$.

\section{DETERMINATION OF SIZE- INDEPENDENT FRACTURE ENERGY}

The intention of this paper is to correlate the peak load $P_{\max }$ with the local fracture energy $g_{f}$ and determine the size-independent fracture energy $G_{\mathrm{F}}$. The crack-tip local fracture energy may affect the $P_{\max }$ as discussed above. To study the influence of the crack-tip $g_{f}$ on the $P_{\max }$, fracture tests of three-point-bending notched granite beams are carried out first to obtain the experimentally measured maximum fracture loads.

\subsection{Experimental programme}

The granite used in the experiment is medium-grain granite with an average grain size between 2-3 $\mathrm{mm}$ and tensile strength of 8 MPa. Two groups of 3-p-b samples are prepared with beam depth of $30 \mathrm{~mm}$ in Group I and $70 \mathrm{~mm}$ in Group II. The span of all the beams is 4 times of the depth. All the specimens have a width of $25 \mathrm{~mm}$.

In Group I $(h=30 \mathrm{~mm})$, the initial crack length is set as $3 \mathrm{~mm}, 6 \mathrm{~mm}, 12 \mathrm{~mm}$ and 18 $\mathrm{mm}$. In the other group $(h=70 \mathrm{~mm})$, the notch length is $2 \mathrm{~mm}, 3 \mathrm{~mm}, 4 \mathrm{~mm}, 6 \mathrm{~mm}, 10 \mathrm{~mm}$, $21 \mathrm{~mm}, 30 \mathrm{~mm}, 38 \mathrm{~mm}, 45 \mathrm{~mm}, 53 \mathrm{~mm}$.

\subsection{Results and discussions}

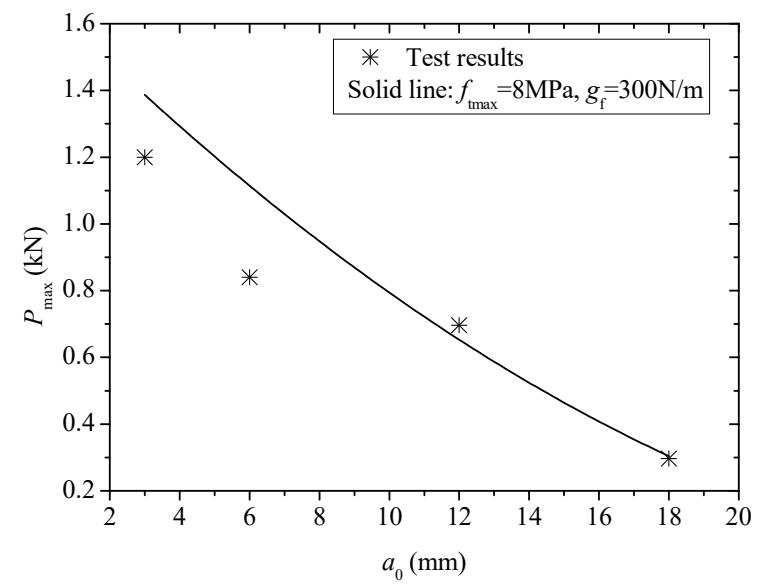

Figure 4: $P_{\max }$ versus $a_{0}$ in Group I $(h=30 \mathrm{~mm})$

The experimentally measured peak loads $P_{\max }$ of all the granite beams are shown in Figs. 4 and 5, respectively. In the proposed analytical approach, the $f_{\text {tmax }}$ is adopted as 8 $\mathrm{MPa}$ and the crack-tip $g_{\mathrm{f}}$ is $300 \mathrm{~N} / \mathrm{m}$. Then the analytically predicted $P_{\max }$ versus the initial crack length $a_{0}$ and its comparison with the experimentally determined $P_{\max }$ are given in Figs. 4 and 5, respectively.

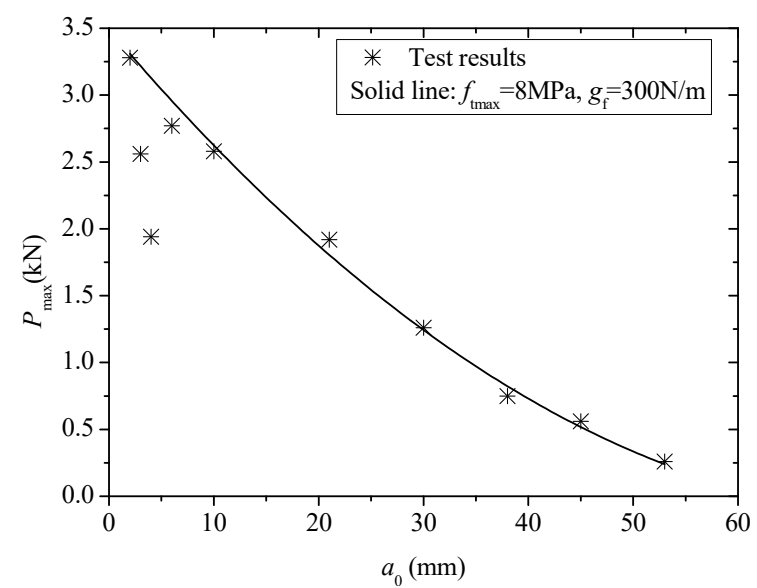

Figure 5: $P_{\max }$ versus $a_{0}$ in Group II $(h=70 \mathrm{~mm})$

There are distinctly two parts in Figs. 4 and 5 according to the comparison between the analytically predicted and experimentally determined maximum fracture loads. When the $a_{0}$ is smaller than $9 \mathrm{~mm}$, most of the scattered points fall below the solid line. It means the analytically predicted $P_{\max }$ is apparently lower than the experimentally measured $P_{\max }$ in this part. In the other part, however, all the scattered points distribute symmetrically along the solid line and good agreement appears between the analytically predicted and experimentally determined $P_{\max }$.

As discussed above, the $f_{\text {tmax }}$ and $g_{\mathrm{f}}$ are two important parameters affecting the loadcarrying capacity. Therefore, the underestimation of $P_{\max }$ for $a_{0}<9 \mathrm{~mm}$ is mainly due to the lower value of $f_{\text {tmax }}$ or $g_{\text {f. Although }}$ the value of the $f_{\text {tmax }}$ is random and variable, it should be a material constant statistically irrelevant to the $a_{0}$. Thus, the only factor is the crack-tip local fracture energy $g_{\text {f. }}$ When $a_{0}$ is longer than $9 \mathrm{~mm}$, the analytically predicted $P_{\max }$ show good agreement with the experimentally determined one and the

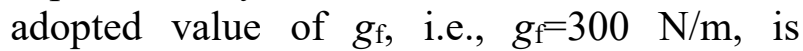
rational. When $a_{0}$ is shorter than $9 \mathrm{~mm}$, the value of $g_{\mathrm{f}}$ must be smaller than $300 \mathrm{~N} / \mathrm{m}$. The value of $a_{0}$ actually reflects the distance from 
the front free boundary according to the literature [21]. When $a_{0}$ is shorter than $9 \mathrm{~mm}$, the crack-tip is very near the front free boundary, and the front free boundary effect on the crack-tip $g_{f}$ becomes significant [21]. Thus, the value of the $g_{\mathrm{f}}$ is relatively low in this part. In addition, the maximum scope affected by the front free boundary effect is about $9 \mathrm{~mm}$ equal to 3 times of the maximum grain size $d_{\max }(3 \mathrm{~mm})$ for the medium-grain granite. When $a_{0}$ is longer than $9 \mathrm{~mm}$, the front free boundary effect gradually disappears and the crack-tip $g_{\mathrm{f}}$ keeps $300 \mathrm{~N} / \mathrm{m}$ as constant. The maximum scope affected by the back free boundary effect should be approximately equal to that by the front free boundary effect [21]. But the longest initial crack lengths are $18 \mathrm{~mm}$ and $53 \mathrm{~mm}$, respectively, in the two groups. Thus, the back free boundary effect can not be detected in the test in this paper. The maximum local fracture energy, i.e., $g_{\mathrm{f}}=300$ $\mathrm{N} / \mathrm{m}$, is also the size-independent fracture energy $G_{\mathrm{F}}$ without any boundary effect for this type of granite. Moreover, a tri-linear model for the local fracture energy distribution along the beam depth can be proposed as follows.

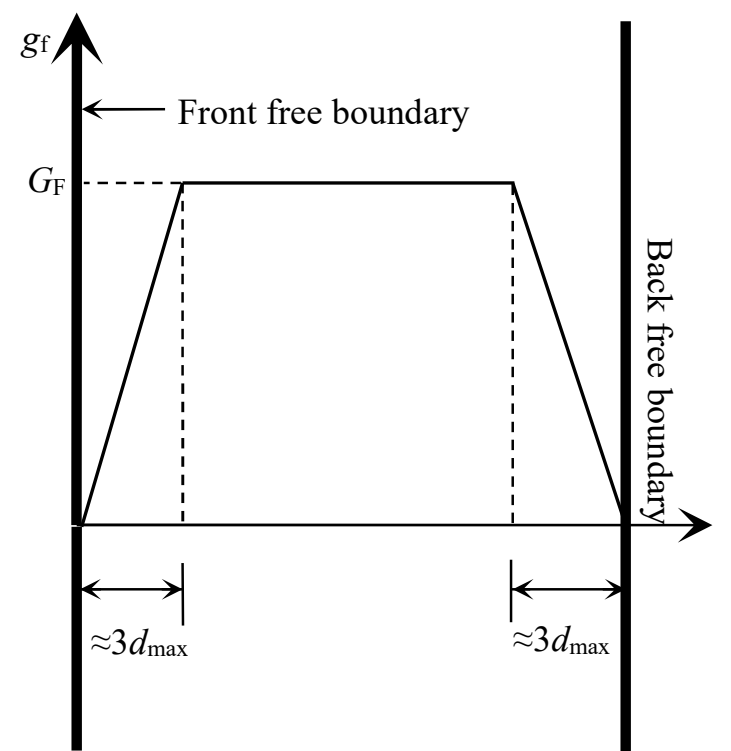

Figure 6: Tri-linear model for local fracture energy distribution of granite

\section{CONCLUSIONS}

Fracture energy, defined as the amount of energy necessary to create one unit area of a crack, is a very important parameter in analyzing the behavior of quasi-brittle materials such as concrete, mortar, rock, et al.. The present study is aimed to determine the size-independent fracture energy of granite by virtue of the peak loads of three-point-bending notched beams. An analytical model was presented to predict the maximum fracture load of granite beams by using Lagrange Multiplier Method. The peak load is then correlated with the crack-tip local fracture energy.

Fracture tests were then carried out on granite beams with two depths, i.e., $30 \mathrm{~mm}$ and $70 \mathrm{~mm}$. For the beams with depths of 30 $\mathrm{mm}$, the notches are cut with lengths from 3 $\mathrm{mm}$ to $18 \mathrm{~mm}$. For the beams with depths of $70 \mathrm{~mm}$, the notch lengths vary from $2 \mathrm{~mm}$ to $53 \mathrm{~mm}$. The average value of the maximum tensile stress at the fictitious crack-tip is adopted as $8 \mathrm{MPa}$. Upon the comparison between the analytically predicted peak loads and the experimentally determined ones, the correlation between the crack-tip local fracture energy and initial crack length can be obtained It can be found that the value of crack-tip local fracture energy almost keeps $300 \mathrm{~N} / \mathrm{m}$ without any boundary effect for the notch lengths from $9 \mathrm{~mm}$ to $18 \mathrm{~mm}$ in the beams with depths of $30 \mathrm{~mm}$ and for the notch lengths from $10 \mathrm{~mm}$ to $53 \mathrm{~mm}$ in the beams with depths of $70 \mathrm{~mm}$. Thus, a tri-linear model for the local fracture energy distribution with the size-independent fracture energy of $300 \mathrm{~N} / \mathrm{m}$ is proposed for this type of granite. The maximum scope affected by the front or back free boundary effect is about 3 times of the maximum grain size of granite.

\section{ACKNOWLEDGEMENT}

The authors gratefully acknowledge funding from the National Natural Science Foundation of China (Grant 51378481).

\section{REFERENCES}

[1] RILEM 50-FCM Draft Recommendation. 1985. Determination of the fracture energy of the mortar and concrete by means of 
three-point bend tests on notched beams. Materials and Structures 18(106): 287-290.

[2] Bažant, Z.P. 1984. Size effect in blunt fracture: concrete, rock, metal. Journal of Engineering Mechanics 110(4): 518-535.

[3] Bažant, Z.P., and Kazemi, M. 1990. Determination of fracture energy, process zone length and brittleness number from size effect, with application to rock and concrete. International Journal of Fracture 44(2): 111-131.

[4] Carpinteri, A., Chiaia, B., and Ferro, G. 1995. Size effects of nominal tensile strength of concrete structures: multifractality of materials ligaments and dimensional transition from order to disorder. Materials and Structures 28(180): 311-317.

[5] Carpinteri, A., and Chiaia, B. 1995. Multifractal nature of concrete fracture surfaces and size effects on nominal fracture energy. Materials and Structures 28(182): 435-443.

[6] Carpinteri, A., and Chiaia, B. 1996. Size effects on concrete fracture energy: dimensional transitions from order to disorder. Materials and Structures 29(189): 259-266.

[7] Hillerborg, A., Modeer, M., and Petersson, P. 1976. Analysis of crack formation and crack growth in concrete by means of fracture mechanics and finite elements. Cement and Concrete Research 6(6): 773782.

[8] Hu, X.Z. and Wittmann, F.H. 1992. Fracture energy and fracture process zone. Materials and Structures 25(6): 319-326.

[9] Hu, X.Z. and Wittmann, F.H. 2000. Size effect on toughness induced by crack close to free surface. Engineering Fracture Mechanics 65(2): 209-221.

[10] Hu, X.Z. 2002. An asymptotic approach to size effect on fracture toughness and fracture energy of composites. Engineering Fracture Mechanics 69(5): 555-564.

[11] Hu, X.Z. and Duan, K. 2004. Influence of fracture process zone height on fracture energy of concrete. Cement and Concrete Research 34(8): 1321-1330.
[12] Hu, X.Z. and Duan, K. 2008. Size effect and quasi-brittle fracture: the role of FPZ. International Journal of Fracture 154(12): 3-14.

[13] Hu, X.Z. and Duan, K. 2010. Mechanism behind the size effect phenomenon. Journal of Engineering Mechanics 136(1): 60-68.

[14] Duan, K., Hu, X.Z. and Wittmann, F.H. 2003. Boundary effect on concrete fracture and non-constant fracture energy distribution. Engineering Fracture Mechanics 70(16): 2257-2268.

[15] Abdalla, H.M. and Karihaloo, B.L. 2003. Determination of size-independent specific fracture energy of concrete from three-point bend and wedge splitting tests. Magazine of Concrete Research 55(2): 133-141.

[16] Muralidhara, S., Raghu Prasad, B.K., Karihaloo, B.L. and Singh, R.K. 2011. Size-independent fracture energy in plain concrete beams using tri-linear model. Construction and Building Materials 25(7): 3051-3058.

[17] Saliba, J., Loukili, A., Grondin, F. and Regoin, J.P. 2012. Experimental study of creep-damage coupling in concrete by acoustic emission technique. Materials and Structures 45(9): 1389-1401.

[18] Vydra, V., Trtík, K., Vodák, F. 2012. Size independent fracture energy of concrete. Construction and Building Materials 26(1): 357-361.

[19] Karihaloo, B.L., Murthy, A.R. and Iyer, N.R. 2013. Determination of sizeindependent specific fracture energy of concrete mixes by the tri-linear model. Cement and Concrete Research 49: 82-88.

[20] Murthy, A.R., Karihaloo, B.L., Iyer, N.R. and Raghu Prasad, B.K. 2013. Determination of size-independent specific fracture energy of concrete mixes by two methods. Cement and Concrete Research 50: 19-25.

[21] Yang, S.T., Hu, X.Z. and Wu, Z.M. 2011. Influence of local fracture energy distribution on maximum fracture load of three-point-bending notched concrete 
beams. Engineering Fracture Mechanics 78(18): 3289-3299.

[22] Yang, S.T., Hu, X.Z., Leng, K.Z. and Liu, Y.L. 2014 Correlation between cohesive crack-tip local fracture energy and peak load in mortar specimens. Journal of Materials in Civil Engineering 26(10): 04014069(1-8).

[23] Vasconcelos, G., Lourenço, P.B. and Costa, M.F.M. 2008. Mode I fracture surface of granite: measurements and correlations with mechanical properties. Journal of Materials in Civil Engineering 20(3): 245-254.

[24] Tada, H., Paris, P. C., and Irwin, G. R. 1985. The stress analysis of cracks handbook, Paris Productions, St. Louis, MO. 